TITLE Histamine Intolerance: why freshness matters.

Author Georgia Ede, MD

Smith College, dr.ede@comcast.net

Keywords histamine, histamine intolerance, low histamine diet, diamine-oxidase deficiency, biogenic amines, food intolerance

Acknowledgments and Disclosures: No financial conflicts of interest to disclose.

\title{
Introduction
}

In some cases, adopting a new dietary pattern with the intention of improving health and wellbeing can produce unintended consequences. Low-carbohydrate high-fat (LCHF), ketogenic, GAPS (Gut and Psychology Syndrome), and "paleo" diets often contain significantly more fermented foods such as aged cheeses, kimchi, and cured meats than conventional diets. This is because fermented foods are intensely flavorful, low in carbohydrate, and often portable and convenient, making these unconventional diets easier to adhere to. However, these same foods also tend to be high in histamine, a powerful biological signaling molecule.

For those with unrecognized Histamine Intolerance, these foods can cause a host of new and uncomfortable symptoms that may mislead people into thinking that low-carbohydrate diets are unhealthy or intolerable. Symptoms may include: migraine headache, localized allergic reactions (rhinitis, angioedema, pruritus, etc.), palpitations, blood pressure fluctuations, asthma, gastrointestinal distress, menstrual cramps, insomnia and fatigue $[1,2]$. Unfortunately, these symptoms are common, generic, and seemingly unrelated, making recognition challenging by patients and clinicians alike. It is estimated that at least $1 \%$ of the population suffers from Histamine Intolerance, $80 \%$ of whom are middle-aged or older [3].

\section{Biogenic amines}

Histamine is just one member of a diverse family of biogenic amines. Biogenic amines are decarboxylated amino acids which can be generated either endogenously for biological purposes, or exogenously as a by-product of microbial fermentation. Within the body, biogenic amines function as potent, short-lived, receptor-mediated intercellular signaling molecules that modulate cell growth, hormone release and neuronal activity [4,5]. After a biogenic amine has bound to its receptor and sent its message, it is immediately inactivated by a neutralizing enzyme [2,5], limiting its effects to the microenvironment in which it was created.

\section{Endogenous histamine}

Histamine is synthesized from the parent amino acid histidine by the enzyme histidine decarboxylase (HDC). This enzyme is stored within specialized cells in the body, as well as in certain types of bacteria and yeast in the environment. Within the human body, mast cells, basophils, gastric enterochromaffin cells, histaminergic neurons, and certain gut bacteria all possess the HDC enzyme and are therefore capable of producing histamine. To make matters more complicated, there are four distinct histamine receptor subtypes in the human body: $\mathrm{H} 1$, $\mathrm{H} 2, \mathrm{H} 3$ and $\mathrm{H} 4$, each with a unique response to histamine binding [6]. Thus, histamine produces 
different effects on nearby cells, depending on which cell type and receptor it binds to, resulting in a staggering variety of potential physiological responses to its release. Examples of the diversity of histamine responses include: vasodilation, uterine contraction, mucus secretion, and neurotransmitter release [3].

\section{Exogenous histamine}

Histamine is not only generated intentionally by specialized cells in the body, it is also created by microorganisms which encounter histidine-containing foods. Plants and animals contain little to no histamine when living, but histamine-producing organisms are ubiquitous, meaning that virtually any human food source that is not absolutely fresh is likely to contain some quantity of histamine. The longer the food has been exposed to these organisms, the higher the level of histamine (and other biogenic amines) tends to be. Moreover, human beings enjoy intentionally adding bacteria and yeast to certain fresh foods and allowing them to age (ferment) —often for many months - to develop more complex flavors. Examples of high-histamine gourmet delicacies include ripened cheeses, dry aged salami, and sauerkraut.

Many species of bacteria populating the human intestine possess HDC and can transform undigested histidine in the fresh foods we eat into histamine under the right circumstances. The first and most powerful line of defense against ingested histamine is diamine oxidase (DAO), a histamine neutralizing enzyme secreted by intestinal epithelial cells into the gut lumen. The highest concentrations of DAO are found in the small intestine and proximal ascending colon, whereas the highest concentrations of gut bacteria are found in the large intestine. Any undigested food proteins that reach the colon will therefore be fermented by resident microbes, generating significant quantities of histamine in an area where there is little DAO available to inactivate it [2].

\section{Histamine Intolerance}

In healthy individuals, DAO can deactivate approximately $50 \mathrm{mg} / \mathrm{kg}$ concentrations of histamine in ingested foodstuffs. Therefore, even people with normal physiology can experience symptoms of histamine overload if exposed to concentrations of histamine above their natural capacity to detoxify it.

There is a second line of defense against histamine--an intracellular enzyme called histamine $\mathrm{N}$ methyl transferase (HNMT) - but this ubiquitous enzyme is thought to play only a minor role in the detoxification of exogenous histamine entering through the gut lining. Indeed, while there are many potential underlying causes of Histamine Intolerance, by far the most common is DAO deficiency. Any condition that temporarily or permanently damages intestinal epithelial cells can reduce DAO secretion rates and therefore allow some histamine to cross from the gut lumen into the bloodstream. Examples include Crohn's Disease, chemotherapy, and Celiac Disease. Other potential causes of Histamine Intolerance include: congenital DAO deficiency, DAO cofactor deficiencies (DAO requires vitamin B6, vitamin C, copper, and zinc to function properly), and small intestinal bacterial overgrowth (SIBO). [2]

\section{Food sources of histamine}

Any food that contains histidine and isn't strictly fresh, and any food that has been intentionally aged, cultured, fermented, cured or smoked will accumulate histamine. The precise amount of 
histamine in any given food will vary depending on numerous variables, including temperature, number and type of microorganisms, and exposure time, making it impossible for consumers with Histamine Intolerance to reliably predict which foods will trigger symptoms. Literature sources cite histamine levels in foods as ranges; some examples are below:

Table I. Histamine levels in foods [7-12]

\begin{tabular}{|c|c|}
\hline \multicolumn{2}{|c|}{ Plant Foods } \\
\hline Eggplant & $26 \mathrm{mg} / \mathrm{kg}$ \\
\hline Spinach & 30 to $60 \mathrm{mg} / \mathrm{kg}$ \\
\hline Avocado & $23 \mathrm{mg} / \mathrm{kg}$ \\
\hline Sauerkraut (fermented cabbage) & up to $229 \mathrm{mg} / \mathrm{kg}$ \\
\hline Miso (fermented soybeans) & 3 to $6 \mathrm{mg} / \mathrm{kg}$ \\
\hline Natto (fermented soybeans) & can reach over $50 \mathrm{mg} / \mathrm{kg}$ \\
\hline \multicolumn{2}{|c|}{ Dairy Products } \\
\hline Sour cream & up to $7 \mathrm{mg} / \mathrm{kg}$ \\
\hline Yogurt & up to $13 \mathrm{mg} / \mathrm{kg}$ \\
\hline Ripened cheeses & 2.21 to $2500 \mathrm{mg} / \mathrm{kg}$ \\
\hline \multicolumn{2}{|c|}{ Meat } \\
\hline Dry aged sausages & up to $357.7 \mathrm{mg} / \mathrm{kg}$ \\
\hline \multicolumn{2}{|c|}{ Beverages } \\
\hline Red Wine & up to $24 \mathrm{mg} / \mathrm{L}$ \\
\hline Champagne & $670 \mathrm{mg} / \mathrm{L}$ \\
\hline Coffee & $<2 \mathrm{mg} / \mathrm{L}$ \\
\hline \multicolumn{2}{|c|}{ Condiments } \\
\hline Ketchup & $22 \mathrm{mg} / \mathrm{kg}$ \\
\hline Red wine vinegar & $4 \mathrm{mg} / \mathrm{L}$ \\
\hline Cider vinegar & $.02 \mathrm{mg} / \mathrm{L}$ \\
\hline \multicolumn{2}{|c|}{ Chocolate } \\
\hline Conventional dark chocolate & 10 to $20 \mathrm{mg} / \mathrm{kg}$ \\
\hline Organic dark chocolate & 2 to $4 \mathrm{mg} / \mathrm{kg}$ \\
\hline
\end{tabular}

Most high histamine foods tend to be high in protein (cheese, cured meats, etc.), but there are a few low-protein plant foods which happen to be naturally higher in the parent amino acid histidine: spinach, tomatoes, and eggplant. These are therefore more susceptible to histamine accumulation than other plant foods [3].

There is also widespread mention in the literature of so-called "histamine trigger foods", which may or may not contain much if any histamine, but which nevertheless are suspected of stimulating endogenous release of histamine $[2,8,13$,$] . Unfortunately, the literature is vague$ about mechanisms, and primary sources of research into this phenomenon are lacking.

\section{Diagnosing Histamine Intolerance}

Patient recognition and clinician diagnosis of Histamine Intolerance can be challenging. The differential diagnosis includes true food allergy, non-histamine food intolerances, mastocytosis (rare), and medication reactions [2]. Diagnostic tests are available, but most have low sensitivity and specificity [2,3]. Intestinal biopsies offer accuracy, but are invasive and expensive, therefore rarely utilized. Serum DAO levels are unstable and therefore unreliable, yielding $50 \%$ false 
negatives. Oral challenge with pure histamine should theoretically be an excellent approach: patients eating a low-histamine diet and are given pure liquid histamine by mouth at doses of 50-75 mg to see if symptoms of Histamine Intolerance can be provoked. Interestingly, this test also yields many false negatives. The main flaw in this test has to do with the fact that we don't encounter pure histamine in nature. Histamine is always accompanied by significant levels of numerous other biogenic amines, such as putrescine and cadaverine, both of which inhibit DAO and therefore lower our tolerance to histamine. Alcohol and many medications also act as DAO inhibitors, therefore tolerance to histamine can vary from day to day, depending on the presence or absence of these other factors [14]. Medications known to reduce DAO activity include NSAIDs, certain antibiotics such as cefuroxime, and pain medications such as codeine. $[2,3]$.

The most reliable and practical clinical diagnostic test for Histamine Intolerance is the 50-minute skin prick test, which has both a sensitivity and specificity of approximately $80 \%[2,15]$. However, as with all food intolerances, there is no substitute for personal experimentation: eating a low-histamine diet to see if symptoms improve, then resuming consumption of highhistamine foods and observing whether symptoms return.

\section{Prevention of histamine exposure}

Symptoms can be minimized and even prevented by 1) avoiding aged, fermented, cured, smoked and cultured foods and beverages, 2) avoiding alcohol, which inhibits DAO activity, 3) being aware of medications that inhibit DAO activity, and 4) perhaps avoiding foods suspected of triggering endogenous histamine release. As histamine is odorless, tasteless and invisible, educating oneself about foods which may contain histamine is paramount. Symptoms of Histamine Intolerance generally commence within about 2 hours and resolve within 24 hours of consuming a high-histamine food or beverage. Keeping a food and symptom journal to observe patterns is key to learning which foods trigger discomfort.

Foods should be purchased as fresh as possible, before a significant amount of histamine has formed. Once formed in a food, histamine is literally indestructible, but its production can be thwarted with proper food handling techniques [12]. Placing fresh foods on ice dramatically slows microorganism metabolism and hence histamine production. Histidine decarboxylase (HDC), the enzyme microorganisms use to create histamine, can be destroyed by cooking or by freezing food for 1-2 weeks, but neither cooking nor freezing destroys histamine-producing organisms. Therefore, foods should be eaten immediately after preparation, and any leftovers should be frozen to minimize further histamine production.

\section{Treatment of Histamine Intolerance}

Antihistamines, mast cell stabilizers, and porcine DAO enzyme supplements can be used to minimize symptoms for those unable or unwilling to adhere to a low-histamine diet, or for those who have been inadvertently exposed to histamine in foods. [2].

\section{Conclusion}

Histamine Intolerance is an important yet under-recognized, preventable, food-induced cause of many common human ailments, from migraines and asthma to palpitations and IBS. More education of clinicians and the general public about how the foods we eat affect our physiology, 
and about Histamine Intolerance in particular, could reduce suffering and empower people to have more control over their well-being.

\section{References}

[1] Komericki P, Klein G, Reider N, Hawranek T, Strimitzer T, Lang R, Kranzelbinder B, Aberer W. Histamine intolerance: lack of reproducibility of single symptoms by oral provocation with histamine: a randomised, double-blind, placebo-controlled cross-over study. Wien Klin Wochenschr. 2011 Jan;123(1-2):15-20. PubMed PMID: 21165702.

[2] Kovacova-Hanuskova E, Buday T, Gavliakova S, Plevkova J. Histamine, histamine intoxication and intolerance. Allergol Immunopathol (Madr). 2015 Sep-Oct;43(5):498-506. PubMed PMID: 26242570.

[3] Maintz L, Novak N. Histamine and histamine intolerance. Am J Clin Nutr. 2007 May;85(5):1185-96. PubMed PMID: 17490952.

[4] Ramani D, De Bandt JP, Cynober L. Aliphatic polyamines in physiology and diseases. Clin Nutr. 2014 Feb;33(1):14-22. PubMed PMID: 24144912.

[5] Grandy D. Trace amine-associated receptor 1 - family archetype or iconoclast? Pharmacol Ther. 2007 Dec;116(3): 355-90. PubMed PMID: 17888514.

[6] Seifert R, Strasser A, Schneider EH, Neumann D, Dove S, Buschauer A. Molecular and cellular analysis of human histamine receptor subtypes. Trends Pharmacol Sci. 2013 Jan;34(1):33-58. PubMed PMID: 23254267.

[7] Byun BY, Mah JH. Occurrence of biogenic amines in miso, Japanese traditional fermented soybean paste. J Food Sci. 2012 Dec;77(12):T216-23. PubMed PMID: 23140362.

[8] Jarisch R, editor. Histamine Intolerance: histamine and seasickness. Berlin: Springer; 2014.

[9] Restuccia D, Spizzirri UG, Puoci F, Picci N. Determination of biogenic amine profiles in conventional and organic cocoa-based products. Food Addit Contam Part A Chem Anal Control Expo Risk Assess. 2015;32(7):1156-63. PubMed PMID: 25833003.

[10] Restuccia D, Spizzirri UG, Parisi OI, Cirillo G, Picci N. Brewing effect on levels of biogenic amines in different coffee samples as determined by LC-UV. Food Chem. 2015 May 15;175:143-50. PubMed PMID: 25577063.

[11] Tsai YH, Chang SC, Kung HF. Histamine contents and histamine-forming bacteria in natto products in Taiwan. Food Control. 2007;18(9):1026-1030.

[12] Hungerford JM. Scombroid poisoning: a review. Toxicon. 2010 Aug 15;56(2):231-43.

PubMed PMID: 20152850. 
[13] Vlieg-Boerstra BJ, van der Heide S, Oude Elberink JN, Kluin-Nelemans JC, Dubois AE. Mastocytosis and adverse reactions to biogenic amines and histamine-releasing foods: what is the evidence? Neth J Med. 2005 Jul-Aug;63(7):244-9. PubMed PMID: 16093574.

[14] Ruiz-Capillas C, Jiménez-Colmenero F. Biogenic amines in meat and meat products. Crit Rev Food Sci Nutr. 2004;44(7-8):489-99. PubMed PMID: 15969322.

[15] Kofler L, Ulmer H, Kofler H. Histamine 50-skin-prick test: a tool to diagnose histamine intolerance. ISRN Allergy. 2011 Feb 22;2011:353045. PubMed PMID: 23724226. 